\title{
ENHANCING ANTERIOR AESTHETICS BY SOFT TISSUE MODULATION USING IMMEDIATE TEMPORIZATION TECHNIQUE- A CASE REPORT
}

\author{
Suvidha S. Patil ${ }^{1}$, Anand Kumar G. Patil2, Raghunath A. Patil ${ }^{3}$, Hema Kanathila ${ }^{4}$
}

\begin{abstract}
${ }^{1}$ Lecturer, Department of Prosthodontics, KAHER'S KLE VK Institute of Dental Sciences, Belgavi, Karnataka, India.
2Professor and HOD, Department of Prosthodontics, KAHER'S KLE VK Institute of Dental Sciences, Belgavi, Karnataka, India.

${ }^{3}$ Professor, Department of Prosthodontics, KAHER'S KLE VK Institute of Dental Sciences, Belgavi, Karnataka, India.

${ }^{4}$ Reader, Department of Prosthodontics, KAHER'S KLE VK Institute of Dental Sciences, Belgavi, Karnataka, India.
\end{abstract}

HOW TO CITE THIS ARTICLE: Patil SS, Patil AKG, Patil RA, et al. Enhancing anterior aesthetics by soft tissue modulation using immediate temporization technique- a case report. J. Evolution Med. Dent. Sci. 2019;8(30):2438-2441, DOI: $10.14260 /$ jemds/2019/534

\section{BACKGROUND}

Pontics in fixed partial dentures must fulfil 3 important requirements: aesthetics, especially in the anterior region, function, and hygiene. In maxillary edentulous regions, ridge defects may preclude a good pontic fit and aesthetic result and dictate the need for surgical augmentation of the collapsed ridge, Hence the modification of ovate pontics designs is proposed to achieve these requirements in fixed partial dentures. This modified design aids to provide proper emergence profile in the edentulous area, hence an aesthetic and functional result can be attained through proper execution of an appropriate surgical technique and adherence to the principles of proper pontic design.

The absence of teeth in the anterior region affects the patient's day-to-day activities and confidence level, therefore achieving good and immediate aesthetics is a prime requirement in dentistry. Patient's desire for naturalappearing tooth replacements has led to the development of designs that help achieve natural appearance of the soft tissues. Specifically, use of the ovate pontic after surgical modification of soft tissue is among the most versatile and effective means of obtaining the desired results. One of most important factors in a treatment of fixed partial denture is to preserve interproximal soft tissue to avoid alveolar bone collapse and to support gingival contours and to eliminate the black triangles. Pontic design is of great significance prior to fixed partial denture reconstruction; the type of pontic influences the surgical procedure if the edentulous area has a ridge defect. If the faciolingual and apico-incisal dimensions of the edentulous ridge are inadequate, a surgical augmentation procedure is often indicated for sculpting an ideal ovate pontic site, creating a gingival profile of an ovate pontic site allows the cervical third of the pontic to merge with the surrounding tissues there by making it appear to have emerged from the alveolar ridge. ${ }^{1}$ The ovate pontic was described by Abrams ${ }^{2}$ in 1980. It was created with a convex shape at the tissue surface to overcome the disadvantages of the ridge lap and modified ridge lap pontics.

'Financial or Other Competing Interest': None.

Submission 14-05-2019, Peer Review 09-07-2019,

Acceptance 15-07-2019, Published 29-07-2019.

Corresponding Author:

Dr. Suvidha S. Patil,

Department of Prosthodontics,

KAHER'S KLE VK Institute of Dental Sciences,

Nehru Nagar, Belgavi-590010,

Karnataka, India.

E-mail: patilsuvidha29@gmail.com

DOI: $10.14260 /$ jemds $/ 2019 / 534$
The convex shape of the ovate pontic improves hygiene, allows correct emergence profile, and is generally considered aesthetically pleasing design. However, in contrast to the various requirements of pontics, which depicts the importance of pressure-free contact over a small area, the ovate pontic comes in contact with a larger area of the underlying soft tissue and applies minimal pressure. ${ }^{3}$

The convex nature of the ovate pontic was created to develop the correct emergence profile and its advantage being its ability to achieve maximum aesthetics and that it is easier to maintain hygiene than the ridge lap types. Its major disadvantage is that it requires a sufficient faciolingual width and apico coronal thickness to house the ovate pontic within the edentulous ridge. If the faciolingual and apico incisal dimensions are inadequate, a surgical augmentation procedure is often indicated.

Patient's desire for aesthetic replacement of missing teeth has initiated to the development of various techniques with aims to achieve a natural appearance of the soft tissues. Specifically, use of the ovate pontic with modifications is the most versatile and effective for obtaining the desired emergence profile. Preparation of pontic site with immediate temporization helps creating a gingival profile of a scalloped architecture there by making it appear to have emerged from the alveolar ridge. Four basic pontic designs have been used over the years: sanitary (hygienic), ridge lap, modified ridge lap, and ovate pontic. In this case report surgical alteration of the residual ridge architecture and immediate temporization with modified pontic design is considered for improving tissue contour which aids in aesthetic and hygiene

The various ridge-modification techniques to aesthetically enhance restorations are as follows: Socket preservation technique-

- Greenstein described this technique to prevent ridge collapse in which bone graft material is applied directly after the extraction of the tooth. ${ }^{4}$

- Full-thickness soft tissue grafts-Meltzer published the first clinical report on using a soft tissue graft solely to correct an aesthetic, anterior vertical ridge defect."

- Seibert described a free-gingiva onlay graft technique to reconstruct the deformed, partially edentulous ridges. ${ }^{5}$

- Pouch procedure- Garber and Rosenberg developed a technique for treating ridges that have a horizontal loss of dimension. It involves the subepithelial placement of a connective tissue graft from the tuberosity." The technique was a refinement of those suggested by Langer and Calagna. ${ }^{6}$

- Immediate pontic technique- Spear suggested a way to maintain the interdental papilla following anterior tooth removal. 
This article describes a technique for placing the modified ovate pontics immediately after soft tissue contouring to imitate the natural emergence profile, ${ }^{6}$ for aesthetics and function.

\section{PRESENTATION OF CASE}

A 40-year-old male patient reported to the Department of Prosthodontics with a chief complaint of missing anterior teeth and he desired replacement to enhance aesthetics. Patient gave history of restoration of anterior teeth with fixed prosthesis 1 year back with dislodgement of FPD within span of 3-5 months. On intra oral examination, it was observed that maxillary 11, 21 and 22 were missing and maxillary alveolar ridge revealed a moderate Siebert Class III defect -combined buccolingual and apicocoronal loss of tissue height with flat gingival architecture (Fig. 1). Based on clinical findings various treatment options were considered and with informed consent from patient, treatment was planned for soft and hard tissue modification with immediate temporization with modified ovate pontics followed by fixed partial prosthesis. Before the procedure was carried out, routine blood investigation was obtained as a procedural protocol. When modifying the ridge surgically it is necessary to know the thickness of soft tissue above the bone which is obtained by probing to the bone, under $2 \%$ (Lidayn- Lignocaine and adrenaline injection) infiltration a careful transgingival probing was carried out. And on bone sounding, it was found that $5 \mathrm{~mm}$ of soft tissue height was available, thus it was concluded that the site required only soft tissue contouring to establish a good emergence profile for the final outcome.

Diagnostic impressions (Zhermack Tropicalgin) were made using irreversible hydrocolloid and cast was poured with type III dental stone, to evaluate the space and diagnostic wax up (Fig 2). Scraping of the cast was done at future site for the modified ovate pontic. Provisional bridge was fabricated in tooth coloured self-cure acrylic resin by indirect technique using putty index. Tissue surface of pontic was kept highly polished so that tissue irritation or plaque accumulation is avoided.

\section{Soft Tissue Modification}

A crestal incision and bilateral releasing incisions were made and conventional gingivoplasty was done to the removal of tissue from the center of the site and outward to the periphery boundary of the ovate pontic with round diamond bur to achieve desirable scalloping of gingival tissues (Fig. 3, 4) and sutured to support the scalloped architecture. The ridge was assessed for adequate tissue height, and bucco-lingual width with sounding of periodontal probe. After haemostasis and clot formation modified ovate pontic was adjusted into the site to support tissue contour, by relining the tissue surface of pontic using self-cure acrylic resin. Cementation of provisional restoration was done with help of eugenol free interim luting agent and immediate placement of restoration allows soft tissue to be supported by pontic (Fig. 5). Patient was given oral hygiene and maintenance instructions.

Patient Recalled after 2 weeks for evaluation followed by crown lengthening with respect to 12 and 23 to get the proper height of contour and proportion of gingival contour for aesthetics.
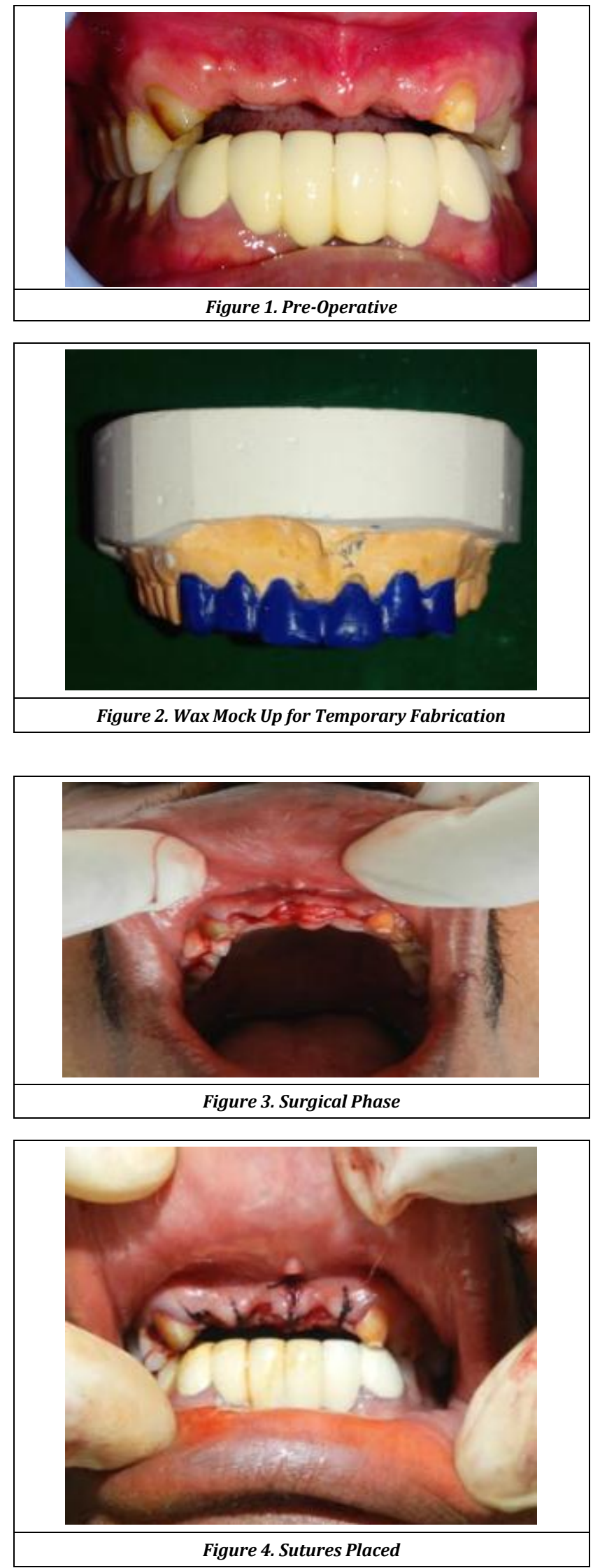

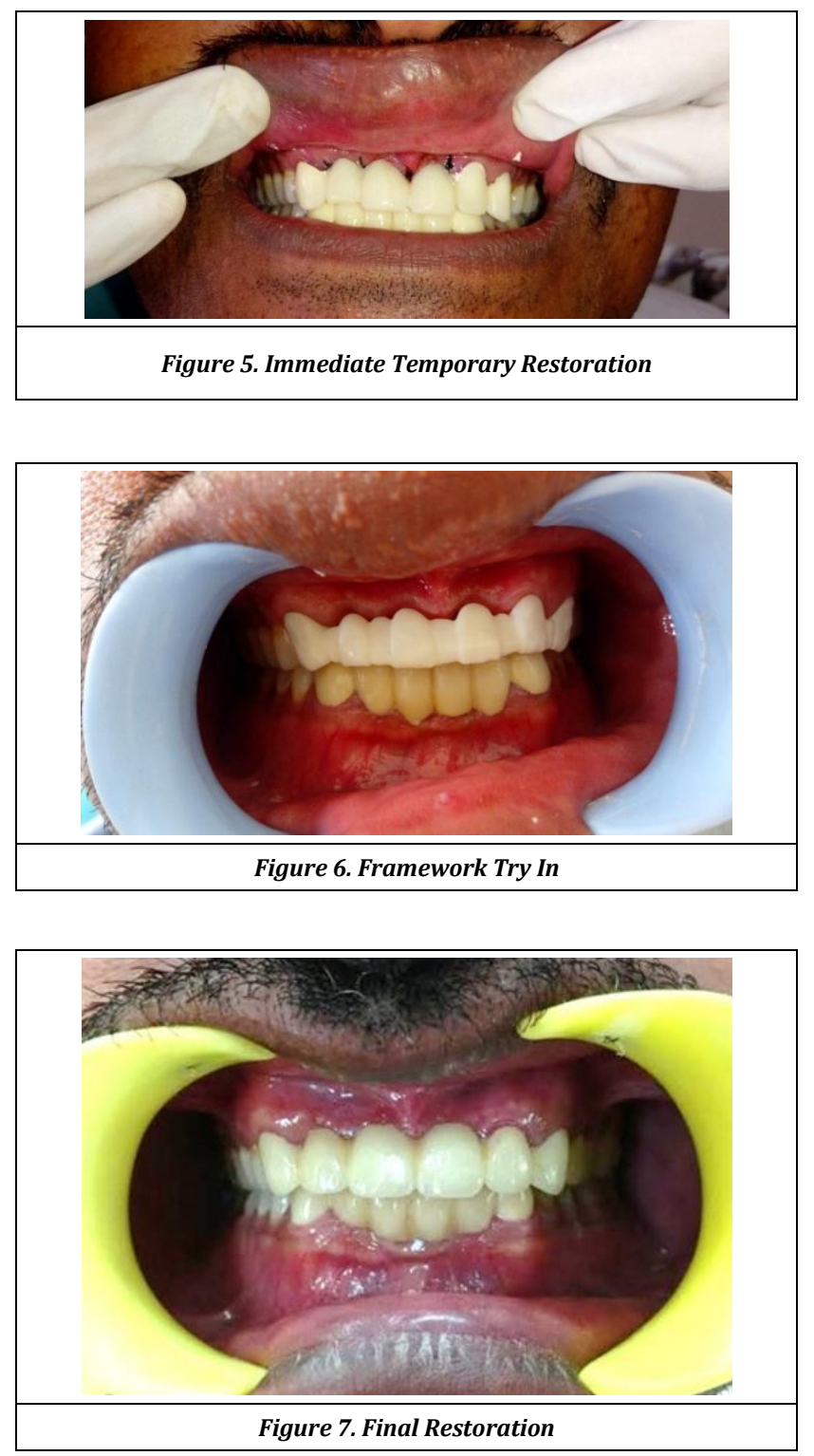

Recall appointments were scheduled after 1 week, 3 weeks, 1 month. At each appointment temporary restoration was removed, made free of debris and tissue condition both at abutment level and pontic was evaluated and irrigated with betadine solution. Tissue surface of pontic was relined using self-cure acrylic resin (DPI-RR cold cure acrylic material) until positive pressure was achieved onto the tissue and temporary prosthesis was recemented with eugenol free luting cement (Freegenol- eugenol free temporary cement). Patient was instructed with oral hygiene and maintenance instructions. Health of soft tissue was assessed by checking the pontic site for absence of inflammation and ulceration. After achieving pink healthy tissue and minimal tissue rebound final tooth preparation and impression was made to receive all ceramic restoration after a time interval of 3 months. (Fig. 6)

Controlled physiologic pressure was considered at pontic area to enhance the interdental papilla and create illusion of pontics emerging from the soft tissue, to create natural looking effect. Patient was given oral hygiene instructions and scheduled recall after 1 month for evaluation. After a month patient was evaluated and checked for function and aesthetics. (Fig. 7)

\section{DISCUSSION}

This article presents a rationale for selection of modified ovate pontic and immediate temporization after surgical modulation of tissues to conventional anterior tooth replacement. Historically different types of pontic design have been used in anterior region like saddle, ridge lap, modified ridge lap and ovate pontics, but to achieve optimal aesthetics after extraction Dewey and Zugsmith advocated the ovate pontic. Convex shape of ovate pontic maintain the presence of interdental papilla, emergence profile and maintain hygiene.

Long term edentulism can lead to loss of bone in all dimensions which makes it difficult in replacement of missing teeth with FPD, hence prosthodontist aims at achieving a favourable emergence profile to make pontic appear as natural as possible. Ovate pontic along with soft tissue procedure was used in this case to mimic the emergence profile, the advantage of ovate pontic is to achieve maximum aesthetics along with positive tissue contact. However, sufficient faciolingual width and apicocoronal thickness are required for housing the ovate pontic. Hence, additional surgical procedures are frequently required to augment the edentulous ridge.

There are many causes of unsuitable pontic site. Two of the most common causes are insufficient compression of alveolar plates after an extraction and non-replacement of a fractured alveolar plate. ${ }^{8}$ Unsuitable pontic site results in unesthetic and nonself-cleansing pontic design, ${ }^{7}$ For favourable pontic design re-contouring of soft and bony tissue may be needed. ${ }^{1}$ When modifying the ridge surgically it is necessary to know the thickness of soft tissue above the bone which is obtained by probing to the bone. A minimum of $2 \mathrm{~mm}$ of tissue height above the bone should be reduced to create a desired pontic form. ${ }^{2}$ On bone sounding, it was found that $5 \mathrm{~mm}$ of soft tissue height was available, and hence it was concluded that the site required only soft tissue contouring to establish a good emergence profile for the final outcome. Conventional procedure over other treatment modalities for pontic site preparation was chosen due to ease of availability and cost effective, and the formation of ovate pontic site started with the removal of tissue from the centre towards periphery boundary of pontic site.

Certain factors should be considered like the gingival margin height should be at ideal level, the ridge tissue should be facial to ideal cervical facial form of the pontic so that the pontic can emerge from the tissue. ${ }^{9}$ Immediate temporization was carried out considering patients aesthetic demands and also for achieving a uniformly convex profile for the seating of the ovate pontic in the final prosthesis.

\section{REFERENCES}

[1] Shinde PH, Dugal R, Kheur M, et al. Soft tissue and hard tissue modulation for enhancing anterior aesthetics. Universal Research Journal of Dentistry 2015;5(2):116-9.

[2] Abrams L. Augmentation of the deformed residual edentulous ridge for fixed prosthesis. Compend Contin Educ Gen Dent 1980;1(3):205-13.

[3] Garber DA, Rosenberg ES. The edentulous ridge in fixed prosthodontics. Compend Contin Educ Dent 1981;2(4):212-23. 
[4] Greenstein G, Jaffin RA, Hilsen KL, et al. Repair of anterior gingival deformity with durapatite. A case report. J Periodontol 1985;56(4):200-3.

[5] Seibert JS. Reconstruction of deformed, partially edentulous ridges, using full thickness only grafts. Part 1. Technique and wound healing. Compend Contin Educ Dent 1983;4(5):437-53.

[6] Langer B, Calagna LJ. The subepithelial connective tissue graft. A new approach to the enhancement of anterior cosmetics. Int J Periodontics Restorative Dent 1982;2(2):23-33.
[7] Spear FM. Maintenance of the interdental papilla following anterior tooth removal. Pract Periodontics Aesthet Dent 1999;11(1):21-28.

[8] Punia V, Lath V, Khandelwal M, et al. The current status of laser application in prosthodontics. NJIRM 2012;3:170-5.

[9] Venkatasubramanyam A, Sigtia S, Sheth E, et al. Laserassisted natural gingival profile creation of an ovate pontic site. J Dent Lasers 2017;11(1):29-32. 